\title{
The effect of riboflavin deficiency in rats on the absorption and distribution of iron
}

\author{
BY HILARY J. POWERS \\ MRC Dunn Nutrition Unit, Milton Road, Cambridge CB4 IXJ \\ A. J. A. WRIGHT AND SUSAN J. FAIRWEATHER-TAIT \\ AFRC Institute of Food Research, Norwich Laboratory, Colney Lane, \\ Norwich NR4 7 UA
}

(Received 6 November 1987 - Accepted 3 December 1987)

1. Riboflavin may play a part in the transport of iron across the gastrointestinal mucosa. Fe absorption was measured in the rat by monitoring whole-body retention of a dose of ${ }^{50} \mathrm{Fe}$ using a small-animal $\gamma$-counter.

2. Female Norwegian Hooded rats were fed on a diet deficient in riboflavin $\left(B_{2}-\right)$ from 5 weeks of age. Control animals, fed on a complete diet $\left(B_{2}+\right)$, were weight-matched to rats fed on the $B_{2}-$ diet. After 7 weeks all rats were fed on a test meal extrinsically labelled with ${ }^{59} \mathrm{Fe}$ and whole-body radioactivity measured for $15 \mathrm{~d}$.

3. Riboflavin deficiency was associated with a reduction in the percentage of the dose absorbed and an increase in the rate of loss of $\mathrm{Fe}$ post absorption.

4. A smaller percentage of the absorbed dose was present in the livers of the riboflavin-deficient animals.

There is little doubt that riboflavin plays some part in iron utilization, and this involvement is almost certainly via a flavin-dependent release of Fe from ferritin (Zaman \& Verwilghen, 1977; Ulrik \& Romslo, 1981; Powers, 1983). The reduction and release of ferritin-bound Fe is important at several stages of Fe metabolism and may be a step in the transport of $\mathrm{Fe}$ across the gastrointestinal mucosa.

Studies conducted in The Gambia, among subjects deficient in riboflavin and with relatively poor Fe status, have suggested that riboflavin may be involved in Fe absorption (Powers et al. 1983, 1985). Powers (1986) has also demonstrated that riboflavin deficiency in the rat impairs the ability of the proximal gastrointestinal mucosa to mobilize ferritin-Fe in vitro. Other workers have also conducted investigations which implicate riboflavin in $\mathrm{Fe}$ absorption (Sirivech et al. 1977; Adelekan \& Thurnham, 1986).

Various problems with experimental design have made the interpretation of some findings difficult and it remains far from clear whether riboflavin is involved in $\mathrm{Fe}$ absorption in vivo. We have therefore chosen to measure $\mathrm{Fe}$ absorption in the rat by monitoring wholebody retention of a dose of ${ }^{59} \mathrm{Fe}$ using a small-animal $\gamma$-counter.

\section{MATERIALS AND METHODS}

Forty 5-week-old female Norwegian Hooded rats were fed on a basal diet containing ( $\mathrm{g} /$ $\mathrm{kg}) 30$ arachis oil, 700 sucrose, 200 casein supplying $0.52 \mathrm{mg}$ riboflavin $/ \mathrm{kg}$ diet, and a vitamin and salt mixture (Powers, 1987). Rats were allocated to one of two dietary regimens to receive either the basal diet $\left(B_{2}-\right)$ or the basal diet plus $15 \mathrm{mg}$ riboflavin $/ \mathrm{kg} \operatorname{diet}\left(\mathrm{B}_{2}+\right)$. Whereas $\mathbf{B}_{2}-$ animals (group 1) were fed ad lib., $\mathbf{B}_{2}+$ animals (group 2) were paired by weight with $B_{2}-$ animals and food intakes restricted so that $B_{2}+$ animals weighed the same as the $\mathrm{B}_{2}-$ partner. Animals were all trained to meal feed so that by 2 weeks on the experimental diets food intake for $1 \mathrm{~d}$ was consumed within a $3 \mathrm{~h}$ period during the morning.

After 7 weeks on the experimental diets all animals were given a fixed amount of diet for 
$3 \mathrm{~d}(12 \mathrm{~g} / \mathrm{meal})$ in order to standardize Fe intakes. Following a $24 \mathrm{~h}$ fast each animal was given a test meal of $3 \mathrm{~g}$ of a paste of cooked starch and sucrose (equal amounts by uncooked weight) containing $120 \mu \mathrm{g} \mathrm{Fe}$ (as ferrous sulphate in $0.1 \mathrm{M}$-hydrochloric acid) extrinsically labelled with $1.0 \mu \mathrm{Ci}{ }^{59} \mathrm{Fe}\left(\mathrm{FeCl}_{3}\right.$; Amersham International plc, Amersham, Bucks). Extrinsic-labelling techniques have been validated as a reliable estimate of absorption of endogenous Fe for several foods (Cook et al. 1972; Weaver et al. 1984). Any rat not consuming at least three-quarters of the test meal within $1 \mathrm{~h}$ was excluded from the experiment. At $4 \mathrm{~h}$ after receiving the test meal all animals on the control diet were given $12 \mathrm{~g}$ food and deficient animals fed $a d$ lib. From this point onwards meal feeding was stopped but weight-matching maintained.

Immediately after consuming the test meal each rat was placed in a small-animal $\gamma$ counter (NE 8112, Nuclear Enterprises, Edinburgh) and whole-body radioactivity monitored, using an external ${ }^{59} \mathrm{Fe}$ standard. The NE 8112 small-animal $\gamma$-counter has a detector made of plastic scintillant in the shape of a well, with a counting chamber $360 \mathrm{~mm}$ long by $170 \mathrm{~mm}$ diameter. Rats were placed in a ventilated Perspex box, 240 by $120 \mathrm{~mm}$ square, with the longitudinal axis of the box coincident with that of the counting chamber. Variation in counts from an isotope point-source at any given position within the counting volume was not more than $1 \%$ of the overall mean, and reproducibility was better than $99 \%$. Animals were counted for $0.5 \mathrm{~min}$, with a counting efficiency of approximately $50 \%$. Radioactivity was monitored every day for $14 \mathrm{~d}$. On the 14 th day after receiving the test meal animals were killed by exsanguination under anaesthesia, and liver, spleen, femur, biceps femoris muscle, $250 \mathrm{~mm}$ of washed proximal small intestine and blood were collected for measurement of the distribution of absorbed ${ }^{59} \mathrm{Fe}$. Measurements were made in a Philips PW4580 automatic $\gamma$-counter and counted using a $75 \times 75 \mathrm{~mm}$ sodium iodide crystal, centre $1180 \mathrm{keV}$, width $440 \mathrm{keV}$, with a counting efficiency of $14 \%$. Riboflavin status was determined at the time of receiving the test meal, in blood collected from the tail vein, and at the time of death, by measuring blood glutathione reductase (NAD(P)H) $(E C$ 1.6.4.2) activation coefficient (BGRAC) (Powers, 1986). Packed cell volumes were measured in blood samples at the time of death of the animals.

\section{RESULTS}

The mean weights of rats at the time of receiving the test meal were 170 (SE 3) g in group 1 and 175 (SE 2) g in group 2. These were not significantly different. One rat in group 2 failed to consume three-quarters of the test meal within $1 \mathrm{~h}$ and therefore has been excluded from the experiment. The riboflavin status of the rats, both at the time of receiving the test meal and at the time of killing are shown in Table 1, expressed as BGRAC; a BGRAC of $>1.30$ is considered to indicate a biochemical deficiency of riboflavin. Rats in group 1 had a significantly higher BGRAC than those of group 2 at both times of measurement, reflecting a depletion of riboflavin.

The mean packed cell volume of rats at the time of killing was 0.414 (SE 0.005) in group 1 and 0.415 (SE 0.007) in group 2. Tissue weights at the time of killing are shown in Table 2. The fresh and dry weights of the proximal $250 \mathrm{~mm}$ of the small intestine were significantly lower in the weight-matched controls than in the riboflavin-deficient rats. No differences were observed for any other tissues measured.

The proportion of ${ }^{59} \mathrm{Fe}$ retained for each day after receiving the test meal is plotted in Fig. 1. The initial rapid fall in whole-body ${ }^{59} \mathrm{Fe}$ activity was due mainly to excretion of unabsorbed ${ }^{59} \mathrm{Fe}$. The daily rate of loss stabilized at day 8 and it is assumed that the subsequent low rate of fall of whole-body ${ }^{59} \mathrm{Fe}$ reflected basal losses. The rate of loss of whole-body ${ }^{59} \mathrm{Fe}$ was calculated for $8-11$ and $8-14 \mathrm{~d}$ after the test meal for each rat, from 


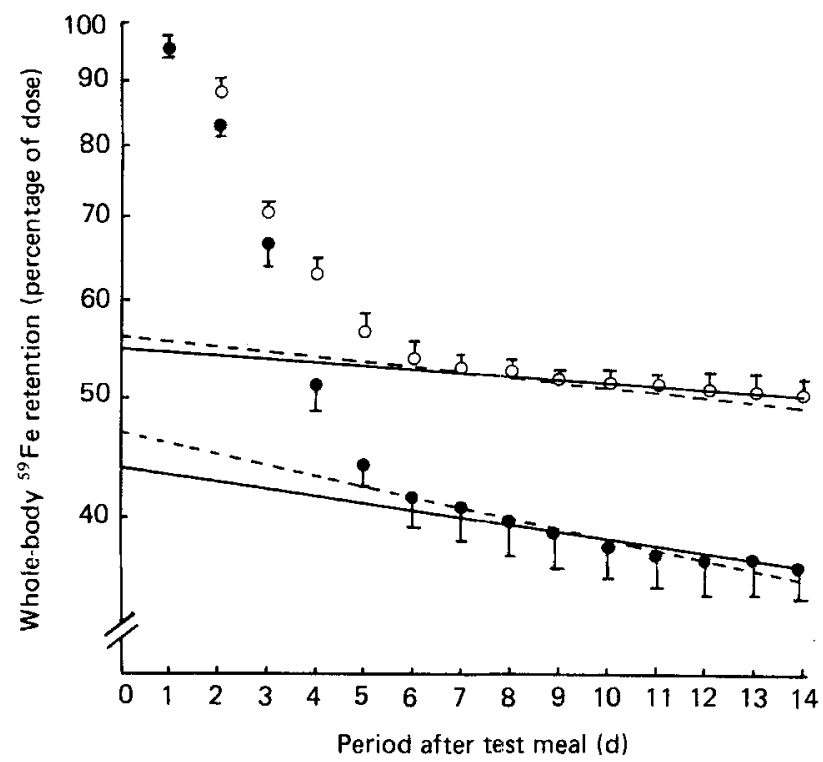

Fig. 1. Whole-body retention of ${ }^{59} \mathrm{Fe}$ from 0 to $14 \mathrm{~d}$ after a ${ }^{59} \mathrm{Fe}$-labelled test meal in control $(O)$ and riboflavin-deficient (O) rats (for details of dietary regimens, see p. 381). Points are means, with their standard errors represented by vertical bars. Log linear regression lines are shown for the periods 8-11 d (--) and 8-14 $\mathrm{d}(-)$ after the ${ }^{59} \mathrm{Fe}$-labelled test meal.

Table 1. Riboflavin status of rats, measured on the day of receiving $a^{59} \mathrm{Fe}$-labelled test meal after 7 weeks on experimental diets, and at the time of killing, $14 d$ later

(Mean values with their standard errors)

\begin{tabular}{|c|c|c|c|c|c|}
\hline \multirow[b]{3}{*}{ Group } & \multirow[b]{3}{*}{ No. of rats } & \multicolumn{4}{|c|}{ BGRAC } \\
\hline & & \multicolumn{2}{|c|}{ Day of test meal } & \multicolumn{2}{|c|}{$14 \mathrm{~d}$ after test meal } \\
\hline & & Mean & $\mathrm{SE}$ & Mean & SE \\
\hline$B_{2}-$ & 20 & $1.64^{*}$ & 0.06 & $1.56^{*}$ & 0.04 \\
\hline $\mathrm{B}_{2}+$ & 19 & 1.28 & 0.02 & $1 \cdot 18$ & 0.03 \\
\hline
\end{tabular}

$\mathrm{B}_{2}-$, rats fed on a riboflavin-deficient diet; $\mathrm{B}_{2}+$, rats fed on a complete diet (control); BGRAC, blood glutathione reductase $(E C 1.6,4.2)$ activation coefficient.

Mean values were significantly different from those of control animals (Student's $t$ test): ${ }^{*} P<0.001$.

a regression of $\log _{10}$ percentage dose ${ }^{59} \mathrm{Fe}$ retained $v$. period (d) after dose. The results are given in Table 3 , and show that the daily rate of loss was significantly higher $(P<0.001)$ in the riboflavin-deficient group than in the controls when calculated over either period. The percentage of dose retained at day 0 was determined by extrapolating the individual regression lines back to day 0 . The values are given in Table 3 and show that predicted retention at day 0 (percentage absorption) was significantly lower in the riboflavin-deficient group, when calculated over either period.

The tissue distribution of absorbed ${ }^{59} \mathrm{Fe}$ is shown in Table 4 . It is evident that the liver of the deficient animals contained a smaller percentage of the absorbed ${ }^{59} \mathrm{Fe}$ than that of the controls, whereas the reverse was true for a $0.5 \mathrm{ml}$ sample of whole blood. The observed difference between the two groups for $250 \mathrm{~mm}$ of proximal small intestine disappeared 
Table 2. Wet weights of tissues from riboflavin-deficient and control rats at the time of killing

(Mean values with their standard errors)

\begin{tabular}{|c|c|c|c|c|}
\hline & \multicolumn{2}{|c|}{ Riboflavin-deficient } & \multicolumn{2}{|c|}{ Weight-matched controls } \\
\hline & Mean & $\mathrm{SE}$ & Mean & $\mathrm{SE}$ \\
\hline Liver & $5 \cdot 292$ & $0 \cdot 142$ & $5 \cdot 405$ & $0 \cdot 143$ \\
\hline Spleen & $0 \cdot 381$ & $0 \cdot 012$ & 0.386 & 0.009 \\
\hline Femur & 0.907 & $0 \cdot 014$ & 0.882 & $0 \cdot 014$ \\
\hline Proximal SI & $1 \cdot 584^{* * *}$ & $0 \cdot 044$ & $1 \cdot 163$ & 0.042 \\
\hline Proximal SI (dry wt) & $0 \cdot 356^{* * *}$ & 0.009 & 0.279 & 0.008 \\
\hline
\end{tabular}

SI, small intestine.

Mean values were significantly different from those of control animals (Student's $t$ test): ${ }^{* * *} P<0.001$.

Table 3. Percentage of ${ }^{59} \mathrm{Fe}$ retained and daily percentage rate of loss of ${ }^{59} \mathrm{Fe}$ retained by rats after an oral dose of $\left[{ }^{59} \mathrm{Fe}\right]$ ferrous sulphate

(Mean values with their standard errors)

\begin{tabular}{|c|c|c|c|c|c|}
\hline \multicolumn{2}{|c|}{ Period after test meal (d)... } & \multicolumn{2}{|c|}{$8-11$} & \multicolumn{2}{|c|}{$8-14$} \\
\hline Group & No. of rats & Mean & $\mathrm{SE}$ & Mean & SE \\
\hline & & \multicolumn{4}{|c|}{ Percentage absorption $\dagger$} \\
\hline $\mathrm{B}_{2}-$ & 20 & $47 \cdot 51^{*}$ & $3 \cdot 11$ & $44 \cdot 29 * *$ & $2 \cdot 75$ \\
\hline $\mathrm{B}_{2}+$ & 19 & $55 \cdot 37$ & 1.29 & $54 \cdot 81$ & $1 \cdot 21$ \\
\hline & & \multicolumn{4}{|c|}{ Daily percentage rate of loss. } \\
\hline$B_{2}-$ & 20 & $2 \cdot 17^{* * *}$ & $0 \cdot 35$ & $1 \cdot 41^{* * *}$ & $0 \cdot 20$ \\
\hline $\mathrm{B}_{2}+$ & 19 & 0.76 & $0 \cdot 11$ & 0.57 & 0.06 \\
\hline
\end{tabular}

$\mathbf{B}_{2}-$, rats fed on a riboflavin-deficient diet; $\mathbf{B}_{2}+$, rats fed on a complete diet (control).

Mean values were significantly different from those of control animals (Student's $t$ test) : ${ }^{*} P<0 \cdot 05,{ }^{* *} P<0 \cdot 01$, *** $P<0.001$.

$\dagger$ Calculated as the percentage dose retained at day 0 , from $\log$ linear regression $v$. period (d) after a ${ }^{50} \mathrm{Fe}-$ labelled test meal as shown.

$\ddagger$ Calculated from the $\log$ linear regression of percentage dose retained $v$. period (d) after a ${ }^{59} \mathrm{Fe}$-labelled test meal as shown.

Table 4. Tissue distribution of absorbed ${ }^{59} \mathrm{Fe}$ (percentage of whole body count) $14 \mathrm{~d}$ after an oral dose of ${ }^{59} \mathrm{Fe}$

(Mean values with their standard errors)

\begin{tabular}{|c|c|c|c|c|}
\hline & \multicolumn{2}{|c|}{$\begin{array}{l}\text { Riboflavin-deficient } \\
(n 20)\end{array}$} & \multicolumn{2}{|c|}{$\begin{array}{l}\text { Weight-matched controls } \\
\qquad(n 19)\end{array}$} \\
\hline & Mean & $\mathrm{SE}$ & Mean & $\mathrm{SE}$ \\
\hline Liver & $30 \cdot 2^{* *}$ & $2 \cdot 1$ & $37 \cdot 4$ & $1 \cdot 1$ \\
\hline Blood $(0.5 \mathrm{ml})$ & $2.98^{* *}$ & $0 \cdot 11$ & $2 \cdot 60$ & 0.07 \\
\hline Spleen & $1 \cdot 34$ & 0.07 & $1 \cdot 31$ & $0-05$ \\
\hline Femur & 0.579 & 0.022 & 0.616 & 0.027 \\
\hline Muscle (per g) & 0.072 & 0.003 & 0.078 & 0.003 \\
\hline Proximal SI & $0.362^{*}$ & 0.017 & 0.306 & 0.019 \\
\hline (per g fresh wt) & 0.232 & $0 \cdot 013$ & $0 \cdot 271$ & 0.020 \\
\hline (per g dry wt) & 1.025 & 0.049 & 1.099 & 0.073 \\
\hline
\end{tabular}

SI, small intestine.

Mean values were significantly different from those of control animals (Student's $t$ test); $P<0 \cdot 05,{ }^{* *} P<0 \cdot 01$. 
when the ${ }^{59} \mathrm{Fe}$ content was expressed on a weight basis, that is ${ }^{59} \mathrm{Fe}(\%$ of total $) / \mathrm{g}$ fresh or dry tissue.

\section{DISCUSSION}

In attempting to clarify whether or not riboflavin deficiency impairs $\mathrm{Fe}$ absorption, great care was taken in controlling for factors now known to influence the absorption of ${ }^{59} \mathrm{Fe}$ from a test meal. Thus all rats received the same concentration of $\mathrm{Fe}$ in the diet, and ate their $24 \mathrm{~h}$ intake as a single meal at the same time daily. It has been clearly demonstrated that dietary $\mathrm{Fe}$ intake during the $3 \mathrm{~d}$ before a test meal influences the amount of ${ }^{59} \mathrm{Fe}$ retained (Fairweather-Tait et al. 1985). Therefore, all rats were given similar levels of Fe for $3 \mathrm{~d}$ before receiving the test meal.

The experiment described here shows very clearly that riboflavin deficiency altered both the absorption of $\mathrm{Fe}$ and the rate of loss of the $\mathrm{Fe}$ absorbed. The difference in rates of postabsorption loss was more marked when calculated over the period 8-11 d after the test meal. This was due to a greater individual variation in daily loss of Fe during days 11-14 after the test meal.

Sirivech et al. (1977) have suggested that riboflavin deficiency may affect Fe absorption via a mucosal oxidoreductase but as they failed to control the marked inanition effect of riboflavin deficiency, interpretation of their findings is difficult. Powers $(1985,1986)$ and Adelekan \& Thurnham (1986) have demonstrated that young riboflavin-deficient rats fail to build up liver $\mathrm{Fe}$ stores as effectively as controls, both groups of workers suggesting that the effect might be due to an impaired Fe absorption. Powers (1986) has also demonstrated that riboflavin deficiency in young and adult rats is associated with a reduction in the in vitro Fe-mobilizing activity of gastrointestinal mucosa, which suggests an effect on $\mathrm{Fe}$ absorption. The monitoring of ${ }^{59} \mathrm{Fe}$ retention using a whole-animal $\gamma$-counter is a sensitive, non-invasive means of measurement of $\mathrm{Fe}$ absorption. We believe that the present study constitutes the first rigorously controlled in vivo demonstration of an impaired absorption of $\mathrm{Fe}$ in riboflavin deficiency.

The elevated post-absorption loss of ${ }^{58} \mathrm{Fe}$ in riboflavin deficiency was entirely unexpected, but was highly significant. The most likely route of this $\mathrm{Fe}$, assuming no gastrointestinal blood loss, is a serosal to mucosal transfer into the small intestine. There is evidence in the literature that such a transfer might take place. Refsum \& Schreiner (1980) observed Fe in goblet cells of the intestinal epithelium and macrophages of the lamina propria of human subjects; they suggested that excretion of $\mathrm{Fe}$ via the goblet cell is a normal feature of $\mathrm{Fe}$ balance. Bjorn-Rasmussen et al. (1980) demonstrated a loss of radioiron from human subjects for up to 1 month after an oral dose, which must represent Fe lost from a nonepithelial part of the intestinal mucosa. In their studies of Fe movement in the rat, Guy \& Schachter (1975) showed in both in vitro and in vivo experiments, that $\mathrm{Fe}$ could be transferred from the serosal to the mucosal surface of the small intestine. Although this is a subject that has received very little attention it does seem as though Fe excretion may play a more significant part in Fe balance than has been hitherto acknowledged. Further studies are required to confirm the route of loss of $\mathrm{Fe}$ in riboflavin deficiency and to clarify the mechanism involved.

The lower percentage of the absorbed $\mathrm{Fe}$ in the livers of the deficient animals is compatible with the reduced accumulation of hepatic ferritin-Fe observed in riboflavin deficiency. This must be a reflection of the need to maintain supply to key tissues, hence limiting the amount of $\mathrm{Fe}$ available for hepatic storage. The erythroid marrow has a high requirement for $\mathrm{Fe}$ which is met in preference to other tissues, which would account for the higher percentage of the total absorbed ${ }^{59} \mathrm{Fe}$ being present in $0.5 \mathrm{ml}$ whole blood from the deficient animals.

Of the tissues weighed, only the proximal small intestine was affected by the different 
dietary regimens. One explanation for the heavier tissue in the riboflavin-deficient group is that the difference was due to different food intakes in the two groups. The weight-matched control animals consumed about $10 \%$ less of the complete diet than the deficient animals. The fine structure of the small intestine is apparently influenced not only by the quality of the diet consumed but also by the actual passage of food down the intestinal tract (Brunser et al. 1968; Williamson, 1978). If, for example, a rat is fed intravenously, even when kept in positive nitrogen balance, it loses gut mass (Levine et al. 1974). It is possible that even this relatively small difference in food intakes by the two groups of rats in the current experiment was responsible for the reduced mass of small intestine in the control group. It is worth noting that if this were to affect Fe absorption at all one would expect it to reduce rather than to enhance absorption in the control group. Alternatively it has been reported that riboflavin deficiency in the mouse is associated with an increased cell turnover rate in the mucous epithelial cells of the small intestine (Miyaji \& Hala, 1965). This may be a mechanism to compensate for an impaired absorption of $\mathrm{Fe}$ in riboflavin deficiency.

It is evident that a moderate riboflavin deficiency in rats receiving a normal supply of dietary Fe was associated with both a reduced absorption of $\mathrm{Fe}$ and an elevated postabsorption loss. The rats were able to maintain a normal packed cell volume, although in our experience liver stores are seriously depleted. If a similar situation prevails in humans then there are important implications. Population groups consuming diets low in riboflavin invariably have low Fe intakes also. It is not uncommon for riboflavin deficiency and poor Fe status to occur simultaneously, and we have demonstrated that in such a situation riboflavin supplements can enhance the haematological response to Fe (Powers et al. 1983).

It is intended that we clarify the effect that low riboflavin intakes have on $\mathrm{Fe}$ absorption in man using a stable isotope of Fe. It is likely that such studies will provide information relevant to preventive and therapeutic approaches to reducing the incidence of Fedeficiency anaemia in vulnerable groups.

The authors would like to thank Mr Terence Cowen and Mrs Jacqui Cooke for skilled care of the animals.

\section{REFERENCES}

Adelekan, D. A. \& Thurnham, D. I. (1986). British Journal of Nutrition 56, 171-179.

Bjorn-Rasmussen, E., Carneskog, J. \& Cederblad, A. (1980). Scandinavian Journal of Haematology 25, $124-126$.

Brunser, O., Reid, A., Mouckeberg, F., Maccioni, A. \& Contreras, I. (1968). American Journal of Clinical Nutrition 21, 976-983.

Cook, J., Layrisse, M., Martinez-Torres, C., Walker, R., Monsen, E. \& Finch, C. A. (1972). Journal of Clinical Investigation 51, 805-815.

Fairweather-Tait, S. J., Swindell, T. E. \& Wright, A. J. A. (1985). British Journal of Nutrition 54, 79-86.

Guy, M. J. \& Schachter, D. (1975). American Journal of Physiology 229, 790-796.

Levine, G., Deren, J., Steiger, E. \& Zinno, R. (1974). Gastroenterology 67, 975-982.

Miyaji, K. \& Hala, Y. (1965). Vitamins 31, 185-191.

Powers, H. J. (1983). International Journal of Vitamin and Nutrition Research 53, 371-376.

Powers, H. J. (1985). Annals of Nutrition and Metabolism 29, 261-266.

Powers, H. J. (1986). Annals of Nutrition and Metabolism 30, 308-315.

Powers, H. J. (1987). Journal of Nutrition 117, 852-856.

Powers, H. J., Bates, C. J. \& Lamb, W. H. (1985). Human Nutrition: Clinical Nutrition 39C, 117-129.

Powers, H. J., Bates, C. J., Prentice, A. M., Lamb, W. H., Jepson, M. \& Bowman, H. (1983). Human Nutrition: Clinical Nutrition 37C, 413-425.

Refsum, S. B. \& Schreiner, B. (1980). Journal of Gastroenterology 15, 1013-1020. 
Sirivech, S., Driskell, J. \& Frieden, E. (1977). Journal of Nutrition 107, 739-745.

Ulrik, R. J. \& Romslo, I. (1981). Biochimica et Biophysica Acta 635, 457-469.

Weaver, C. M., Nelson, N. \& Elliott, J. G. (1984). Journal of Nutrition 114, 1042-1048.

Williamson, R. C. N. (1978). New England Journal of Medicine 298, 1393-1402.

Zaman, Z. \& Verwilghen, L. (1977). Biochemical Society Transactions 5 , 306-308. 